\title{
Влияние природы растворителей на сорбционные свойства тонкослойных пластинок «Sorbfil», модифи- цированных наночастицами тиакаликс[4]арен/SiO 2
}

\author{
Танеева А.В. ${ }^{1}$, Зиатдинова Р.В. ${ }^{2}$, Стойков И.И. ${ }^{2}$, \\ Новиков В.Ф. ${ }^{1}$, Будников Г.К. ${ }^{2}$ \\ ${ }^{1}$ Казанский государственный энергетический университет, Казань \\ ${ }^{2}$ Казанский (Приволжский) федеральный университет; Химический институт им. А.М.Бутлерова, \\ Казань
}

Поступила в редакцию 5.07.2018 г.

DOI: https://doi.org/10.17308/sorpchrom.2018.18/615

Проведена оценка влияния физико-химической природы органических растворителей на сорбционные свойства силикагеля, модифицированного наночастицами тиакаликс[4]арен/SiO 2 , в условиях восходящей тонкослойной хроматографии на пластинках «Sorbfil». Установлено, что модификация поверхности тонкослойных пластинок наноструктурированным модификатором приводит к существенному повышению времени удерживания органических растворителей, что может служить способом регулирования селективности разделения анализируемых сорбатов. Найдены закономерности, связывающие длину сорбционного слоя со временем удерживания стандартных сорбатов, а также оценен их вклад в тип межмолекулярного взаимодействия в системе сорбат-сорбент.

Ключевые слова: растворители, сорбция, нанопорошок, тонкослойные пластинки, силикагель, элюент, модификация, поверхность, энергия, температура, разделение.

\section{Effect of solvents nature on the sorption properties of thin plates «Sorbfil», modified with nanoparticles thiacalix[4]arene/ $\mathrm{SiO}_{2}$}

\author{
Taneeva A.V. ${ }^{1}$, Ziyatdinova R.V. ${ }^{2}$, Stoikov I.I. ${ }^{2}$, \\ Novikov V.F. ${ }^{1}$, Budnikov G.K. ${ }^{2}$ \\ ${ }^{1}$ Kazan State Power Engineering University, Kazan \\ ${ }^{2}$ Kazan (Volga region) Federal University, Alexander Butlerov Institute of Chemistry, Kazan
}

By the method of ascending thin-layer chromatography on thin-layer plates «Sorbfil» modified by thiacalix nanoparticles[4] aren/SiO2, the influence of the nature of organic solvents on the sorption properties of the obtained new material was evaluated. N-hexane, ethyl acetate, methylethylketone, toluene, characterized by various physical and chemical properties, were used as organic solvents.

The nanopowder thiacalix[4]arene/SiO2 were obtained using ultrasonic treatment. The solvent front movement was determined by the modified thin-layer plate in comparison with the standard sorbent «Sorbfil». The retention time of the solvent was fixed every $10 \mathrm{~mm}$. The influence of the nature of organic solvents on the sorption properties of thin-layer plates modified by the studied nanoparticles was established. For polar solvents, characterized by sufficiently large dipoles of molecules, there is a significant increase in the retention time along the length of the sorption layer of the modified thin-layer plate.

Based on the method of Braun's assessed contribution to the intermolecular interaction with different polarity of solvents for thin-layer plates «Sorbfil», modified with nanoparticles, thiacalix[4]arene/SiO2 in 
comparison with unmodified and shows the displacement of the experimental points in different area of a triangular system.

Keywords: solvents, sorption, nanopowder, thin-layer plates, silica gel, eluent, modification, surface, energy, temperature, separation

\section{Введение}

В настоящее время тонкослойная хроматография широко используется в различных отраслях промышленности для контроля технологических процессов, а также в научных исследованиях. Она применяется для анализа биологически активных соединений [1-3], исследования бумажных документов и чернил [4-6], а также для установления давности выполнения штрихов рукописных текстов [7]. Кроме того, тонкослойная хроматография используется для диагностики маслонаполненного оборудования по анализу фурановых производных, образующихся в трансформаторном масле в результате деструкции бумажной изоляции, а также определения антиокислительных присадок [8].

Обычно в качестве сорбционных материалов в тонкослойной хроматографии наиболее широко используют силикагель, который наносится со связующим компонентом на инертную подложку. С целью улучшения селективных характеристик силикагеля его, как правило, модифицируют различными органическими и неорганическими веществами, например, мицелярными подвижными фазами при варьировании природы и концентрации поверхностно-активных веществ и органических растворителей [9-14].

В тонкослойной хроматографии большую роль играют растворители, так как их химическая природа влияет на селективность разделения анализируемых сорбатов в условиях восходящей тонкослойной хроматографии.

Оценка влияния физико-химической природы органических растворителей на сорбционные свойства силикагеля, модифицированного наночастицами тиакаликс[4]арен $/ \mathrm{SiO}_{2}$, в условиях восходящей тонкослойной хроматографии на тонкослойных пластинках «Sorbfil» и является целью настоящей работы.

\section{Эксперимент}

Экспериментальную часть работы проводили с использованием тонкослойных пластинок марки «Sorbfil» с сорбционным слоем из молотого и фракционированного по размерам частиц крупнопористого силикагеля марки КСК. Тонкослойные пластинки «Sorbfil» производятся в промышленном масштабе, рекомендованы к применению в аналитических лабораториях промышленных предприятий и в основном удовлетворяют требованиям отечественных потребителей. Однако по ряду технологических показателей они уступают тонкослойным пластинкам зарубежных производителей.

С целью улучшения сорбционных характеристик тонкослойных пластинок «Sorbfil» проведено их модифицирование наночастицами тиакаликс [4]арен/ $\mathrm{SiO}_{2}$. В качестве растворителей использовали органические вещества, характеризующиеся различными температурами кипения и полярными свойствами. Для расчета вклада в величины удерживания стандартных сорбатов пользовались треугольной системой координат Брауна [15], которую ранее применяли для оценки сорбционных свойств фосфор- и мышьякорганических неподвижных фаз для газовой хроматографии [16]. 


\section{Обсуждение результатов}

В таблице 1 приведены физико-химические свойства растворителей, применяемых в качестве элюэнтов для разделения и анализа компонентов в тонкослойной хроматографии, а также их времена удерживания по длине сорбционного слоя 100 мм. Как видно из таблицы, исследуемые растворители имеют разную температуру кипения от $68^{\circ} \mathrm{C}$ для н-гексана до $110.6^{\circ} \mathrm{C}$ для толуола и характеризуются различными дипольными моментами. При этом, несмотря на более высокую температуру кипения толуола, он характеризуется низкими значениями времени удерживания, что, очевидно, связывается с его более объёмной молекулой, когда капиллярный эффект затруднен и сорбция протекает преимущественно на границе раздела фаз жидкость твердое тело. При модификации поверхности тонкослойной пластинки наночастицами тиакаликс[4]арен/ $\mathrm{SiO}_{2}$ за существенное повышение времени удерживания наблюдается в случае этилацетата, метилэтилкетона и толуола, и не меняется для $\boldsymbol{H}_{\text {- }}$ гексана, что очевидно связано с облегчением стерической доступности молекул указанных растворителей к сорбционным центрам поверхности сорбента за счет уменьшения свободной поверхностной энергии частиц силикагеля. В этом случае энергия сорбции увеличивается и времена удерживания повышаются.

Таблица 1. Физико-химические свойства растворителей для тонкослойной хроматографии 15].

$\mathrm{T}_{\text {кип }}{ }^{\circ} \mathrm{C}$ - температура кипения; Д 20 - дипольный момент; $\mathrm{E}_{20}$ - показатель преломления; $\mu$ - вязкость; $\mathrm{t}_{\mathrm{x}}$ - время удерживания на длине сорбционного слоя силикагеля в $100 \mathrm{mm;} \mathrm{t}_{\mathrm{m}}$ - время удерживания на длине сорбционного слоя в 100 мм на модифицированном силикагеле.

\begin{tabular}{|c|c|c|c|c|c|c|c|c|c|}
\hline$﹎{\mathbf{o}_{\text {пा }}}$ & Растворитель & формула & $\begin{array}{c}\mathrm{T}_{\text {кип, }} \\
{ }^{\circ} \mathrm{C}\end{array}$ & Д $_{20}$ & $\mathrm{E}_{20}$ & $\begin{array}{c}\mu, \\
\text { мПа·20 }\end{array}$ & $\begin{array}{c}\mathrm{t}_{\mathrm{x}}, \\
\text { мин }\end{array}$ & $\begin{array}{c}\mathrm{t}_{\mathrm{м}}, \\
\text { мин }\end{array}$ & $\begin{array}{c}\Delta \mathrm{t} \\
\text { мин }\end{array}$ \\
\hline 1 & н-Гексан & $\mathrm{C}_{6} \mathrm{H}_{4}$ & 68.0 & 0.05 & 1.90 & 0.32 & 65 & 65 & 0 \\
\hline 2 & Этилацетат & $\mathrm{C}_{4} \mathrm{H}_{8} \mathrm{O}_{2}$ & 77.1 & 2.48 & 6.00 & 0.45 & 25 & 84 & 59 \\
\hline 3 & Метилэтилкетон & $\mathrm{C}_{4} \mathrm{H}_{8} \mathrm{O}$ & 79.6 & 2.84 & 19.00 & 0.30 & 12 & 38 & 26 \\
\hline 4 & Толуол & $\mathrm{C}_{7} \mathrm{H}_{8}$ & 110.6 & 0.06 & 2.30 & 0.58 & 18 & 37 & 19 \\
\hline
\end{tabular}

Интересно отметить, что для гексана как на немодифицированном, так и на модифицированном силикагеле время удерживания практически не меняется. Так как н-гексан относится к неполярным сорбатам с дипольным моментом молекулы близким к нулю, то в данном случае разделение на тонкослойной пластинке с силикагелем в обоих случаях осуществляется в основном по дисперсионному механизму.

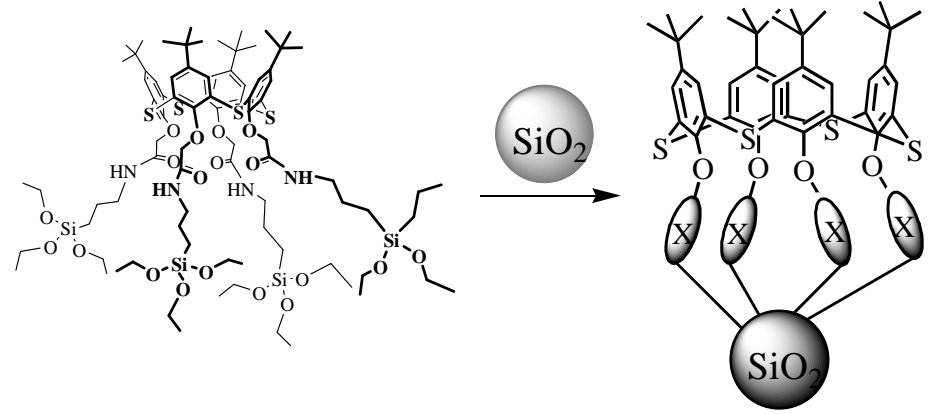

Рис. 1. Схема получения поверхностно модифицированного нанодисперсного порошка диоксида кремния - тиакаликс[4]арен/ $\mathrm{SiO}_{2}$

На рис.1 приведена схема получения нанодисперсного порошка диоксида кремния, который диспергировали в ацетоне и наносили с помощью пульверизатора на тонкослойную пластинку «Sorbfil». Затем ее сушили в термостате при температу-

Tанеева и др. / Сорбционные и хроматографические процессы. 2018. Т. 18 . № 6 
pe $80^{\circ} \mathrm{C}$ для удаления паров растворителя и в условиях восходящей тонкослойной хроматографии определяли их сорбционные свойства по отношению к органическим растворителям различной физико-химической природы.

Тиакаликс[4]арен/ $\mathrm{SiO}_{2}$ наночастицы. 0.306 г нанопорошка диоксида кремния (Sigma Aldrich, 12 нм, площадь поверхности составляет 175-225 м²/г (BET)) диспергировали в $25 \mathrm{~cm}^{3}$ ледяной уксусной кислоты при ультразвуковой обработке, затем добавляли 0.0306 г тиакаликсарена (в конфигурации конус). Через 60 мин (пульс 5/5) ультразвуковой обработки при мощности диспергирования $40 \%$ от максимальной коллоидную суспензию оставляли на 24 ч для конденсации кремнийорганического производного тиакаликсарена на поверхности наночастиц. Далее коллоидную суспензию промывали ацетоном $\left(3 \times 30 \mathrm{~cm}^{3}\right)$. Ацетон отделяли от частиц центрифугированием. Полученный влажный порошок растворяли в 24 мл ацетона при ультразвуковой обработке и затем сушили. Исходный материал обладает термической и гидролитической устойчивостью до температур более $300^{\circ} \mathrm{C}$.

Тонкослойные пластины разрезали на полоски шириной 10 мм, которые опускали в виалу с растворителем и через каждые 10 мм фиксировали время элюирования.

На рис.2. приведена схема движения фронта растворителя (метилэтилкетона) по длине сорбционного слоя силикагеля для тонкослойных пластинок с «Sorbfil» (a) и модифицированными наночастицами (б). Как видно из рис. 2, фронт движения метилэтилкетона для «Sorbfil» характеризуется вогнутым мениском, то есть наблюдается краевой эффект, когда скорость движения растворителя у краев тонкослойной пластинки выше, чем в середине. На модифицированном силикагеле фронт растворителя выправляется, и краевого эффекта не наблюдается.

(a)

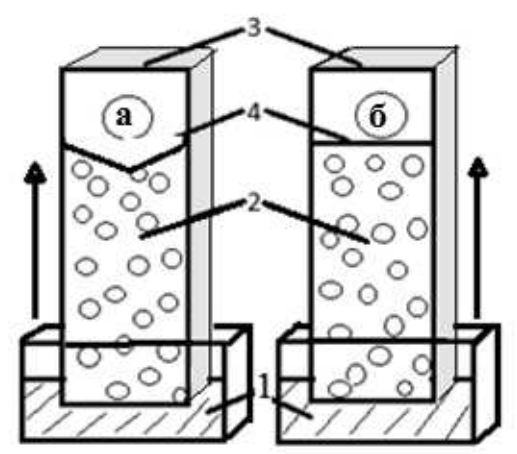

Рис. 2. Фронт движения растворителя по тонкослойной пластинке: (a) - тонкослойная пластинка с «Sorbfil»; (б) - тонкослойная пластинка, модифицированная наночастицами тиакаликс[4]арен/ $\mathrm{SiO}_{2}$.

1-растворитель; 2 -сорбент; 3- тонкослойная пластинка; 4- фронт движения растворителя.

На рис. 3 приведена зависимость времени удерживания толуола на тонкослойной пластинке «Sorbfil» (1) и модифицированной Тиакаликс[4]арен/ $/ \mathrm{SiO}_{2}$ (2) от длины сорбционного слоя.

Как видно из рис. 3, эта зависимость является нелинейной в области длины сорбционного слоя до 40-50 мм, затем ход экспериментальных кривых выпрямляется. При этом модификация тонкослойных пластинок «Sorbfil» приводит к существенному повышению времени удерживания толуола, что указывает на усиление межмолекулярного взаимодействия донорно-акцепторной природы в процессе подъема растворителя по длине сорбционного слоя. Аналогичная зависимость наблюдается для этилацетата (рис.4). 


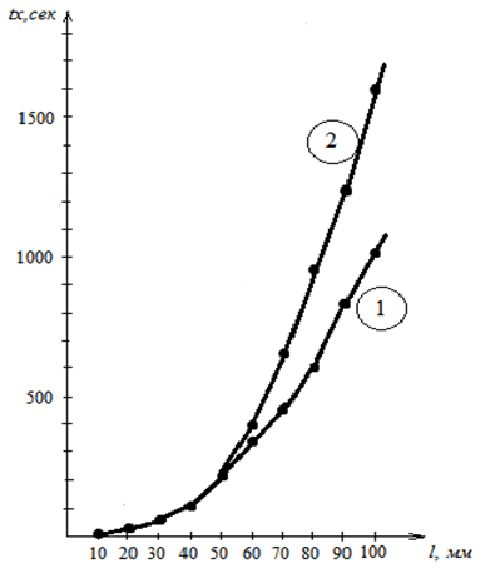

Рис. 3. Зависимость времени удерживания толуола ( $t x$, сек) на немодифицированной (1) и модифицированной наночастицами тиакаликс[4]арен/SiO 2 (2) тонкослойной пластинке «Sorbfil» от длины сорбционного слоя $(l, \mathrm{Mм})$

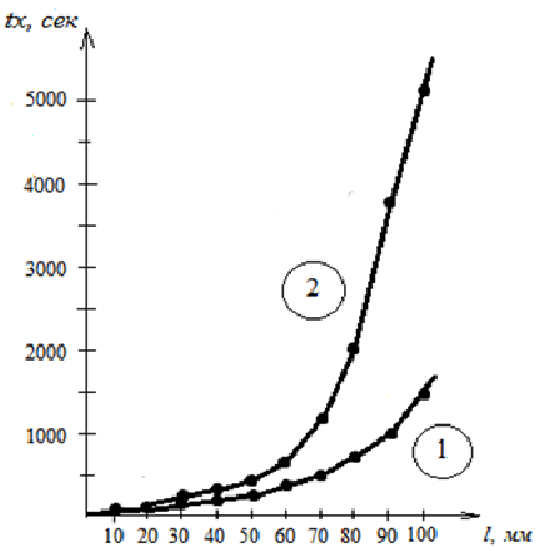

Рис. 4. Зависимость времени удерживания этилацетата $t x$, сек на немодифицированной (1) и модифицированной наночастицами тиакаликс[4] арен/ $\mathrm{SiO}_{2}(2)$ тонкослойной пластинке «Sorbfil» от длины сорбционного слоя $l$, мм

Однако в этом случае разница во временах удерживания на тонкослойной пластинке «Sorbfil» и модифицированном тиакаликс[4]арен/ $\mathrm{SiO}_{2}$ является более существенной и составляет около 60 мин. Такое существенное различие во временах удерживания сорбатов на тонкослойных пластинках, модифицированных наночастицами тиакаликс[4]арен/ $/ \mathrm{SiO}_{2}$, позволяет регулировать селективность разделения анализируемых компонентов, обусловленную модификацией используемых тонкослойных пластинок и варьированием природы органических растворителей (элюэнтов). Следует отметить, что для н-гексана, имеющего дипольный момент близкий к нулю, такой зависимости не наблюдается и соответствующие кривые сливаются. Очевидно, это связано с тем, что неполярный н-гексан может вступать во взаимодействие только по дисперсному механизму. А время удерживания толуола и этилацетата увеличивается за счет специфических сил межмолекулярного взаимодействия донорно-акцепторной природы.

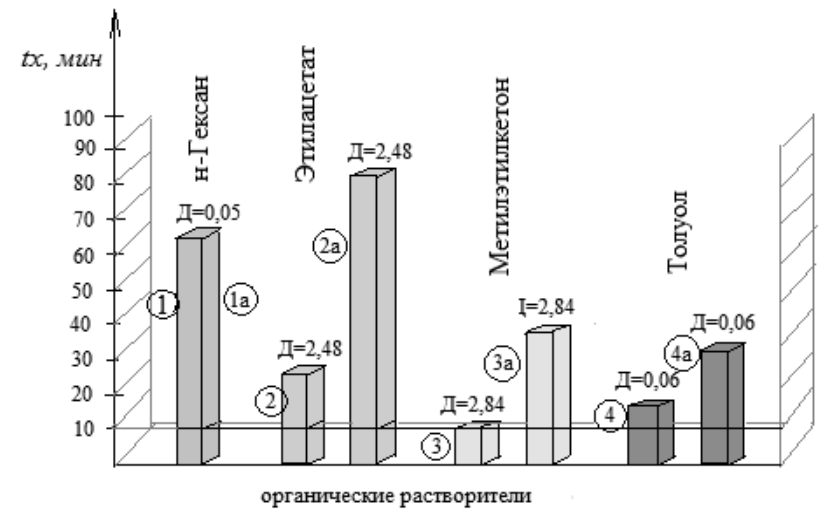

Рис. 5. Зависимость абсолютного времени удерживания органических растворителей от их природы. 1 - н-Гексан; 2- этилацетат; 3 - метилэтилкетон; 4 - толуол; 1-4 - тонкослойная пластина «Sorbfil»; 1a - 4a - тонкослойная пластина «Sorbfil», модифицированная наночастицами тиакаликс[4]арен/ $\mathrm{SiO}_{2}$

На рис.5 приведена зависимость абсолютного времени удерживания органических растворителей от их природы. Как видно из рис., для тонкослойных пласти- 
нок с «Sorbfil» н-гексан, имеющий более низкую температуру кипения, чем этилацетат, метилэтилкетон и толуол, характеризуется большим значением абсолютного времени удерживания, что свидетельствует о преимущественно дисперсионном механизме сорбции неполярных соединений. При модификации поверхности «Sorbfil» наноструктурированным тиакаликс[4]арен $/ \mathrm{SiO}_{2}$ характер приведенной зависимости изменяется в сторону существенного повышения времен удерживания сорбатов, способных к специфическому межмолекулярному взаимодействию с поверхностью наноструктурированного сорбента. При этом наиболее высокие значения времени удерживания наблюдаются для этилацетата, который характеризуется высоким значением дипольного момента (Д=2.48).

С целью оценки вклада в межмолекулярные взаимодействия различных по полярности растворителей был построен треугольный график Брауна, приведенный на рис.6.

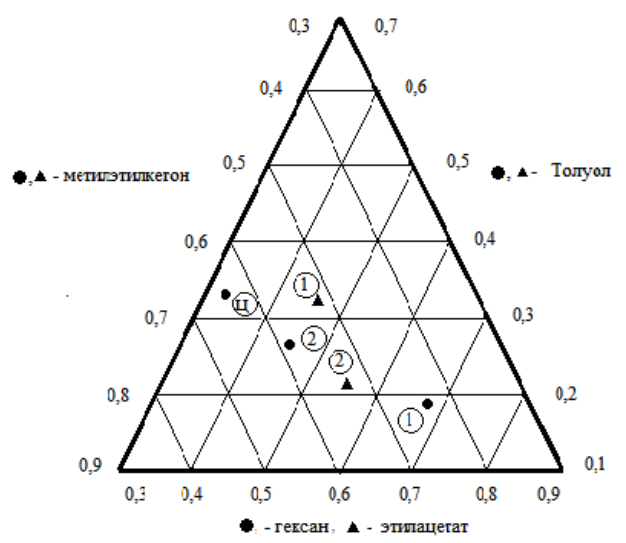

Рис. 6. Оценка вклада в межмолекулярные взаимодействия различных по полярности растворителей для тонкослойных пластинок «Sorbfil» (1) и модифицированных наночастицами тиакаликс[4]арен/ $\mathrm{SiO}_{2}(2)$. Ц - центр симметрии треугольной диаграммы. Сорбаты: • - н-гексан, метилэтилкетон, толуол; $\boldsymbol{\Delta}$ - этилацетат, толуол, метилэтилкетон.

Как видно из рис.6, точки, соответствующие исследуемым растворителям, смещены от центра симметрии треугольной диаграммы в правую область. При этом в системе координат н-гексан, метилэтилкетон, толуол для тонкослойных пластинок «Sorbfil» экспериментальные точки смещены в область высоких значений долей удерживания н-гексана, что подтверждает ранее высказанное положение о дисперсионном механизме разделения. При модификации тонкослойной пластинки наноструктурированным силикагелем экспериментальные точки смещаются в левую область треугольной диаграммы ближе к ее центру симметрии. В данном случае на сорбционную способность тонкослойной пластинки начинает оказывать влияние природа модификатора, а именно тиакаликс[4]арен/ $\mathrm{SiO}_{2}$.

В системе координат этилацетат, метилэтилкетон, толуол характер приведенной картины изменяется, различие вклада сорбатов в общую величину хроматографического удерживания становится менее заметным, т.е. в данном случае оказывает влияние роль конкурирующих факторов в процесс межмолекулярного взаимодействия в системе сорбат-сорбент.

\section{Заключение}

Тонкослойные пластинки с сорбционным слоем силикагеля «Sorbfil», модифицированные наночастицами тиакаликс[4]арен/ $\mathrm{SiO}_{2}$, обладают более высокими 
сорбционными свойствами и могут быть использованы в аналитической химии для разделения и анализа различных по физико-химической природе органических смесей.

\section{Список литературы}

1. Платонов И.А., Другов Ю.С., Родин А.А. Практическая аналитическая химия. Самара. ООО «Порто-принт». 2015. 550 с.

2. Измайлов Н.А., Шрайбер М.С. Открытие тонкослойной хроматографии. Под ред. В.Г.Березкина. М. ГЕОС. 2007. 128 с.

3. Красиков В.Д. Основы планарной хроматографии. СПб. Химиздат. 2005. 232 с.

4. Kuran Z.R. // J. of Forensic Science.1986. No 31. pp.655-657.

5. Crown D., Brunelle R., Canto A. // J. of Forensic Science. 1976. No 21. pp. 917-922.

6. Tappolet J. // Forensic Science Jnt. 1983. No 22. pp.99-109.

7. Агинский В.Н. Установление давности выполнения штрихов рукописных текстов. М. ЭКЦ МВД РФ. 1997. 8c.

8. Карташова А.А., Новиков В.Ф. // Известия высших учебных заведений. Проблемы энергетики. 2016. № 1-2. С. 138-145.

9. Сумина Е.Г., Штыков С.Н., Сорокина О.Н., Петракова А.В и др. // Сорбционные и

\section{References}

1. Platonov I.A., Drugov Yu.S., Rodin A.A. Uch.allowance., Samara, LLC "Porto-print", 2015, $550 \mathrm{p}$.

2. Izmailov N.A., Shraiber M.S. ,Otkrytie tonkosloinoi khromatografii, Pod red. V.G. Berezkina, M., GEOS, 2007, p.128

3. Krasikov V.D., Osnovy planarnoi khromatografii, SPb., Khimizdat, 2005, pp.232.

4. Kuran Z.R., J. of Forensic Science, 1986, No 31, pp. 655-657.

5. Crown D., Brunelle R., Cantu A., J. of Forensic Science, 1976, pp. 917-922.

6. Tappolet J., Forensic Science Jnt, 1983, No 22, pp. 99-109.

7. Aginskii V.N., Ustanovlenie davnosti vypolneniya shtrikhov rukopisnykh tekstov, M., EKTs MVD RF, 1997, p. 8.

8. Kartashova A.A., Novikov V.F., Izvestiya vysshikh uchebnykh zavedenii. Problemy energetiki, 2016, No 1-2, pp. 138-145.

9. Sumina E.G., Shtykov S.N., Sorokina O.N., Petrakova A.V. et al., Sorbtsionnye i khromato- хроматографические прочессы. 2014. Т.14. № 1. C. $52-62$

10.Беланова Н.А., Карпов С.И., Селеменев В.Ф., Чепелева Е.О. и др. // Сорбиионные и хроматографические проиессы. 2011. Т.11. № 6. C.905-912

11.Сумина Е.Г. // Сорбциионные и хроматографические прочессы. 2010. Т.10. № 1. C.150-160.

12.Armstrong D.W., Terril R.Q. // J.Anal.Chem. Sos. 1983. Vol.105., No 10. pp.2962-2964.

13. Armstrong D.W., Terril R.Q. // J. Anal. Chem. 1979. Vol. 51. No 13. pp. 2160-2167.

14.Сумина Е.Г., Штыков С.Н., Тюрина Н.В.//Журнал аналитической химии. 2003. T.58. № 8. C. 808-819.

15.Лурье А.А. Хроматографические материалы. М. Химия. 1978.440 с.

16.Brown J. // G.Chromatogr. 1063. Vol. 10. pp. 284-293.

graficheskie protsessy, 2014, Vol. 14, No 1, pp. 52-62.

10. Belanova N.A., Karpov S.I., Selemenev V.F., Chepeleva E.O. et al., Sorbtsionnye $i$ khromatograficheskie protsessy, 2011, Vol. 11, No 6, pp. 905-912.

11. Sumina E.G., Sorbtsionnye i khromatograficheskie protsessy, 2010, Vol. 10, No 1, pp. 150-160.

12. Armstrong D.W., Terril R.Q., J.Anal.Chem. Sos., 1983, Vol. 105, No 10, pp.2962-2964.

13. Armstrong D.W., Terril R.Q., Anal. Chem., 1979, Vol. 51, No 13, pp. 2160-2167.

14. Sumina E.G., Shtykov S.N., Tyurina N.B., J. of Analyt. Chem., 2003, Vol. 58, No 8, pp. 808-819.

15. Lur'e A.A., Khromatograficheskie materialy, M., Khimiya, 1978, 440p.

16. Brown J., G.Chromatogr, 1063, Vol. 10, pp. 284-293. 
Танеева Алина Вячеславовна - доцент, кандидат химических наук, Казанский государственный энергетический университет, кафедра Энергообеспечения предприятий и энергоресурсосберегающих технологий, Казань

Новиков Вячеслав Федорович - профессор, доктор химических наук, Казанский государственный энергетический университет, кафедра Энергообеспечения предприятий и энергоресурсосберегающих технологий, Казань

Зиатдинова Рамиля Василовна - аспирант Казанский (Приволжский) федеральный университет, Химический институт им. А.М. Бутлерова, кафедра Органической химии, Казань

Стойков Иван Иванович - профессор, доктор химических наук, Казанский (Приволжский) федеральный университет, Химический институт им. А.М.Бутлерова, кафедра Органической химии, Казань

Будников Герман Константинович - профессор, доктор химических наук, Казанский (Приволжский) федеральный университет, Химический институт им. А.М. Бутлерова, кафедра Аналитической химии, Казань
Taneeva Alina V. - associate Professor, candidate of chemical Sciences, Kazan state power engineering University, Department Of energy supply of enterprises and energy-saving technologies, Kazan: alinataneeva@mail.ru

Novikov Vyacheslav F. - Professor, doctor of chemical Sciences, Kazan state power engineering University, Department Of energy supply of enterprises and energy-saving technologies, Kazan

Ziyatdinova Ramilya V. -PhD student, Kazan Federal University, Chemical Institute. A. M. Butlerov, Department of Organic chemistry, Kazan

Stojkov Ivan I. - Professor, doctor of chemical Sciences, Kazan (Volga region) Federal University, Chemical Institute. A. M. Butlerov, Department of Organic chemistry, Kazan

Budnikov Herman K. - Professor, doctor of chemical Sciences, Kazan (Volga region) Federal University, Chemical Institute. A. M. Butlerov, Department of Analytical chemistry, Kazan 